\title{
Effects of interpregnancy interval and outcome of preceding pregnancy on present pregnancy outcome
}

\author{
Sona Soni ${ }^{1}$, Bharti Singh ${ }^{2 *}$, Veena Agarwal $^{3}$ \\ ${ }^{1}$ Department of Obstetrics and Gynecology, GMC, Bhopal, Madhya Pradesh, India \\ ${ }^{2}$ Department of Obstetrics and Gynecology, AIIMS, Bhopal, Madhya Pradesh, India \\ ${ }^{3}$ Department of Obstetrics and Gynecology, GRMC, Gwalior, Madhya Pradesh, India
}

Received: 23 January 2019

Accepted: 05 March 2019

\author{
*Correspondence: \\ Dr. Bharti Singh, \\ E-mail: drbharti01@gmail.com
}

Copyright: (C) the author(s), publisher and licensee Medip Academy. This is an open-access article distributed under the terms of the Creative Commons Attribution Non-Commercial License, which permits unrestricted non-commercial use, distribution, and reproduction in any medium, provided the original work is properly cited.

\begin{abstract}
Background: The objective of the present study was to estimate the effects of interpregnancy interval and outcome of preceding pregnancy on present pregnancy outcome.

Methods: This study was undertaken as observational study. 1000 women were included in this study then interpregnancy interval categorized in 4 groups. Outcome of preceding pregnancy were included in term of induce abortion, miscarriage, still birth and live birth.

Results: For each group the highest rate of IA occur for woman whose previous pregnancy ended with an IA. For pregnancy after an IA the rate of subsequent IA is $16.6 \%, 11.6 \%, 5 \%$ for IPI of $<6$ month, $6-14$ months and $27-50$ months respectively. Overall lowest rate of IA found for IPI of 27-50 months following live birth i.e. $1.25 \%$ and for group III $2 \%$ only. Rate of miscarriage was higher for IPI of <26 months began with a miscarriage $15.6 \%$ and $13.6 \%$ for following live birth.

Conclusions: Outcome of present pregnancy not only depend upon interpregnancy interval but also depend upon outcome of preceding pregnancy. So, outcome of previous pregnancy will also determine outcome of present pregnancy.
\end{abstract}

Keywords: Induced abortion (IA), Interpregnancy interval (IPI), Miscarriage

\section{INTRODUCTION}

One of the most important goals of Family Planning program is to assist women in achieving an optimal spacing between births. In the past, it was common for married women to bear many children. Most women married at a young age and began to have children from the start of their puberty through the end of their reproductive age (ages 15-49). This was a natural course that occurred when there was no use of contraceptives. ${ }^{1}$ Many years later, the world underwent numerous developments in various aspects including social, economic, and public health. These have led to the changes of the pattern of marriage, the use of contraceptives, and fertility rate. Changes in the fertility rate, the use of contraceptive, and the increase in the average marriage age have influenced birth intervals. Information about how the effects of IPIs vary by the type of outcome that began the interval can help medical practitioners better tailor the advice they give to women about how long they should wait after one pregnancy before trying to become pregnant again. An "optimum" birth interval is defined as the interval associated with the greatest probability of giving birth to a normal full-term infant and with the lowest risks of adverse outcomes to the mother and the preceding child. ${ }^{2,3}$ 
One of the most important goals of India's Family Planning program is to assist women in achieving an optimal spacing between births. Pregnancies that occur before a woman has time to regain her health status, replenish her maternal stores (particularly of folate and red blood cells), restore her hormonal balance, or to establish strong bonds with her previous new born create physical and mental stress that can lead to serious medical complications for both her and her next new born. An optimal birth interval has been shown to promote the health of both mother and infant. It also enables parents to devote more time to each child in the early years, gives parents more time for activities other than child-rearing, and often eases pressure on family finance. ${ }^{4}$ Thus, the researcher was interested in studying the impacts of birth intervals on the health of the mother and child and which birth interval has mostly affected on the mother and child as well as the health impact in each birth order. The results of the study can be useful for policy formation and developing a population and health plan for mother's and child's health. The objective ofpresent study is to estimate the effects of the duration of the preceding IPI on pregnancy outcomes (live birth, stillbirth, spontaneous fetal loss prior to 28 weeks, and induced abortion). We also investigate whether the effects of IPI differ depending on the type of pregnancy outcome that began the interval.

\section{METHODS}

After approval of the ethical committee this observation study was conducted in Department of Obstetrics and Gynaecology. All the patients admitted in hospital during study period. We include outcome of index pregnancy and outcome of preceding pregnancy and IPI calculated.

\section{Inclusion criteria}

- All the pregnant patients $2^{\text {nd }}$ gravida onward and parity $<4$, irrespective of their gestation

- All the ANC patients with age between 20-30 years.

- ANC patient's education $>10^{\text {th }}$ standard

- ANC patients who belong to socioeconomic status beyond the middle socioeconomic class.

\section{Exclusion criteria}

- ANC patients with age $>30$ years and age $<20$ years

- All ANC patients with bleeding disorder, multiple pregnancy

- $\quad$ All cases of contracted pelvis and CPD.

All information has been collected about the date of previous pregnancy outcome either induced abortion, miscarriage, still birth or live birth, date of LMP so enabling measurement of the duration of the IPI. We measure the IPI as the number of months between the date of the outcome of preceding pregnancy and date of the LMP before the index pregnancy. Interpregnancy interval, defined as the number of months between a woman's last pregnancy outcome and the date of the last menstrual period for the pregnancy under study.

Our multivariate analysis control for variable that may affect pregnancy spacing and whether the pregnancy resulted in live birth. The additional explanatory variable is pregnancy parity. The women's age and education, her husband's education, household space (a proxy for the household's economic status), religion, whether the pregnancy was intended and the calendar year and calendar month of the outcomes.

\section{Statistical analysis}

The data of the present study were fed into the computer and after its proper validation, checking for error, coding and decoding were compiled and analysed with the help of SPSS 11.5 software for windows. Appropriate univariate and bivariate analysis and ANOVA (analysis of variance) for more than two means were carried out using t-test and 2 tests were calculated and tested. All means are expressed as mean standard deviation. The critical values for the significance of the results were considered at 0.05 levels.

\section{RESULTS}

All the results compared with IPI of 27-50 months following live birth. Distribution of previous pregnancy outcome that began the IPI according to length of IPI i.e. as IPI is increasing number of adverse pregnancy outcome, IA, miscarriage and SB decreasing. $80 \%$ live birth in group IV and $42 \%$ live birth in group I. Number of non-live birth also decreasing as duration of IPI is increasing.

In group I - IPI of $<6$ months, percentage of induced abortion following induced abortion is $16.6 \%$ following miscarriage $5 \%$ and following live birth $7 \%$. Percentage of miscarriage maximum following miscarriage $15.6 \%$, following induced abortion $10 \%$ and following live birth $13.3 \%$ i.e. even if outcome of preceding pregnancy was live birth and IPI of <6-month, percentage of induced abortion and miscarriage is also higher and total percentage of live birth was only $74.2 \%$ while in group III and group IV $90 \%$ and $91.75 \%$ respectively.

If IPI between 6-14 months percentage of IA is highest following IA and percentage of still birth is highest following still birth and percentage of live birth is higher following live birth. Even in all category's percentage of live birth highest following live birth. In group III and group IV percentage of live birth is higher following live birth.

This indicate previous pregnancy outcome also affect present pregnancy outcome as rate of adverse pregnancy outcome i.e. IA, miscarriage and still birth higher following IA, miscarriage and still birth. For each group the highest rate of IA occurs for woman whose previous 
pregnancy ended with an IA. For pregnancy after an IA the rate of subsequent IA is $16.6 \%, 11.6 \%, 5 \%$ for IPI of $<6$ month, 6-14 months and 27-50 months respectively. Overall lowest rate of IA found for IPI of 27-50 months following live birth i.e. $1.25 \%$ and for group III $2 \%$ only. Rate of miscarriage was higher for IPI of $<26$ months began with a miscarriage $15.6 \%$ and $13.6 \%$ for following live birth. Lowest rate of miscarriage founded for group IV $2.5 \%$ and for group III $3 \%$ following live birth. Rate of miscarriage following miscarriage is higher in all groups in this study. For each group rate of live birth were highest following still birth and low following live birth.
Table 2 is showing, as IPI is increasing number of induced abortions, miscarriages, still births decreases, and number of live births is increasing. Difference is significant $\mathrm{p}$ value $<0.0001$.

Table 5 is showing that rate of induced abortion is highest of IPI began with induced abortion $11.5 \%$ and rate of still birth is highest if IPIs began with still birth $13.6 \%$.

Rate of live birth highest if IP began with live birth $86.6 \%$. When result of individual category compared with reference category then difference is significant.

Table 1: Group distribution.

\begin{tabular}{|l|l|l|l|}
\hline Group & IPI & $\%$ of total sample & \% of total sample \\
\hline I & $<6$ months & 140 & 14 \\
\hline II & $6-14$ months & 160 & 16 \\
\hline III & $15-26$ months & 300 & 30 \\
\hline IV & $27-50$ months & 400 & 40 \\
\hline
\end{tabular}

Table 2: Distribution of previous pregnancy outcome that began IPI according to length of IPI.

\begin{tabular}{|l|l|l|l|l|l|}
\hline IPI & Induced abortion A & Miscarriage B & Still birth C & Live birth D & Total \\
\hline I (<6 months) & 30 & 32 & 18 & 60 & 140 \\
\hline II (6-14 months) & 18 & 30 & 22 & 90 & 160 \\
\hline III (15-26 months) & 20 & 50 & 30 & 200 & 300 \\
\hline IV (27-50 months) & 20 & 32 & 28 & 320 & 400 \\
\hline
\end{tabular}

$\mathrm{P}=<0.0001$, significant

Table 3: Distribution of present pregnancy outcomes that began IPI according to length of IPI.

\begin{tabular}{|c|c|c|c|c|c|c|c|c|c|}
\hline \multirow{3}{*}{ IPI } & \multicolumn{8}{|c|}{ Outcome of index pregnancy } & \multirow{3}{*}{ Total } \\
\hline & \multicolumn{2}{|c|}{ Induced abortion A } & \multicolumn{2}{|c|}{ Miscarriage B } & \multicolumn{2}{|c|}{ Still birth $\mathbf{C}$} & \multicolumn{2}{|c|}{ Live birth D } & \\
\hline & No. & $\%$ & No. & $\%$ & No. & $\%$ & No. & $\%$ & \\
\hline I (<6 months) & 12 & 8.5 & 18 & 11.25 & 6 & 4.2 & 104 & 74.2 & 140 \\
\hline II (6-14 months) & 7 & 4.3 & 11 & 6.8 & 8 & 5 & 134 & 83.75 & 160 \\
\hline III (15-26 months) & 6 & 2.1 & 14 & 4.66 & 9 & 3 & 271 & 90 & 300 \\
\hline IV (27-50 months) & 7 & 1.75 & 14 & 3.5 & 12 & 3 & 367 & 91.75 & 400 \\
\hline
\end{tabular}

$\mathrm{P}=<0.0001$, significant

Table 4: Percentage of index pregnancy ending in induced abortion miscarriage, still birth, live birth by duration of preceding IPI <6 months and type of preceding pregnancy outcome reference category.

\begin{tabular}{|c|c|c|c|c|c|c|c|c|c|}
\hline \multirow{3}{*}{$\begin{array}{l}\text { IPI }<6 \text { months began with outcome } \\
\text { of preceding pregnancy }\end{array}$} & \multicolumn{8}{|c|}{ Outcome of index pregnancy } & \multirow[t]{3}{*}{ Total } \\
\hline & \multicolumn{2}{|c|}{ Induced abortion A } & \multicolumn{2}{|c|}{ Miscarriage B } & \multicolumn{2}{|c|}{ Still birth $\mathbf{C}$} & \multicolumn{2}{|c|}{ Live birth D } & \\
\hline & No. & $\%$ & No. & $\%$ & No. & $\%$ & No. & $\%$ & \\
\hline Induced abortion (A) & 5 & 16.6 & 3 & 10 & 1 & 3.3 & 21 & 70 & 30 \\
\hline Miscarriage (B) & 1 & 3.1 & 5 & 15.6 & 2 & 6.2 & 24 & 75 & 32 \\
\hline Still birth $(\mathrm{C})$ & - & - & 2 & 11.1 & 1 & 5.5 & 15 & 83 & 18 \\
\hline Live birth (D) & 7 & 11.6 & 8 & 13.3 & 2 & 3.3 & 43 & 71.6 & 60 \\
\hline Total & 12 & 8.5 & 18 & 11.5 & 6 & 4.2 & 104 & 74.2 & 140 \\
\hline \multicolumn{10}{|c|}{ Reference category } \\
\hline IPI $27-50$ months began with live birth & 4 & 1.25 & 8 & 2.5 & 6 & 1.8 & 302 & 94 & 320 \\
\hline
\end{tabular}

$\mathrm{P}=<0.0001$, Significant 
Table 5: Percentage of index pregnancy ending in induced abortion miscarriage, still birth, live birth by duration of preceding IPI (6-14 months) group II and type of preceding pregnancy outcome.

\begin{tabular}{|c|c|c|c|c|c|c|c|c|c|}
\hline \multirow{3}{*}{$\begin{array}{l}\text { IPI -6-14 months began with } \\
\text { outcome of preceding pregnancy }\end{array}$} & \multicolumn{8}{|c|}{ Outcome of index pregnancy } & \multirow{3}{*}{ Total } \\
\hline & \multicolumn{2}{|c|}{ Induced abortion A } & \multicolumn{2}{|c|}{ Miscarriage B } & \multicolumn{2}{|c|}{ Still birth C } & \multicolumn{2}{|c|}{ Live birth D } & \\
\hline & No. & $\%$ & No. & $\%$ & No. & $\%$ & No. & $\%$ & \\
\hline Induced abortion (A) & 2 & 11.5 & 1 & 5.5 & 1 & 5.5 & 14 & 77.4 & 18 \\
\hline Miscarriage (B) & - & - & 3 & 10 & 2 & 6.6 & 25 & 83 & 30 \\
\hline Still birth (C) & - & - & 2 & 9 & 3 & 13.6 & 22 & 81 & 22 \\
\hline Live birth (D) & 5 & 5.5 & 4 & 4.4 & 3 & 3.3 & 78 & 86.6 & 90 \\
\hline Total & 7 & 4.3 & 11 & 6.8 & 8 & 5 & 134 & 83.75 & 160 \\
\hline \multicolumn{10}{|c|}{ Reference category } \\
\hline IPI $27-50$ months began with live birth & 4 & 1.25 & 8 & 2.5 & 6 & 1.8 & 302 & 94 & 320 \\
\hline
\end{tabular}

Table 6 is showing that even if IPI of 15-26 months and if IPI began with induced abortion then rate of IA is $5 \%$, compared with IPIs of 15-26 months began with live birth rate of IA only $1.5 \%$. Rate of miscarriage is highest if IPIs began with miscarriage $10 \%$ and $6.6 \%$ if IPI began with still birth while rate of miscarriage only $3 \%$, if IPI began with live birth and difference is significant. This indicate previous pregnancy outcome also affect present pregnancy outcome. Rate of live birth also highest if IPI began with live birth $93 \%$ and only $83 \%$ if IPI began with still birth.
Table 7 showing that if IPI of 27-50 months and IPIs began with live birth then rate of induced abortion is only $1.5 \%$, rate of miscarriage any $2.5 \%$ and live birth $94 \%$. $p$ value is significant $\mathrm{p}<0.003$.

Rate of miscarriage is highest $10 \%$ if IPI began with induced abortion and following miscarriage 9.3\%. Rate of still birth following still birth is $10.7 \%$ and while rate of still birth following live birth only $1.8 \%$ and difference is significant.

Table 6: Percentage of index pregnancy ending in induced abortion miscarriage, still birth, live birth by duration of preceding IPI (15-26 months) preceding IPI and type of preceding pregnancy outcome.

\begin{tabular}{|c|c|c|c|c|c|c|c|c|c|}
\hline \multirow{3}{*}{$\begin{array}{l}\text { IPI } 15-26 \text { months began with } \\
\text { outcome of preceding pregnancy }\end{array}$} & \multicolumn{8}{|c|}{ Outcome of index pregnancy } & \multirow{3}{*}{ Total } \\
\hline & \multicolumn{2}{|c|}{ Induced abortion A } & \multicolumn{2}{|c|}{ Mis-carriage B } & \multicolumn{2}{|c|}{ Still birth C } & \multicolumn{2}{|c|}{ Live birth D } & \\
\hline & No. & $\%$ & No. & $\%$ & No. & $\%$ & No. & $\%$ & \\
\hline Induced abortion (A) & 1 & 5 & 1 & 5 & 1 & 5 & 17 & 85 & 20 \\
\hline Miscarriage (B) & 1 & 2 & 5 & 10 & 2 & 4 & 42 & 84 & 50 \\
\hline Still birth (C) & 1 & 3.3 & 2 & 6.6 & 3 & 10 & 24 & 80 & 30 \\
\hline Live birth (D) & 3 & 1.5 & 6 & 3 & 4 & 2 & 187 & 93 & 200 \\
\hline Total & 6 & 2 & 14 & 4.66 & 9 & 3 & 271 & 90 & 300 \\
\hline \multicolumn{10}{|c|}{ Reference category } \\
\hline IPI 27-50 months began with live birth & 4 & 1.25 & 8 & 2.5 & 6 & 1.8 & 302 & 94 & 320 \\
\hline
\end{tabular}

Table 7: Percentage of index pregnancy ending in induced abortion miscarriage, still birth, live birth by duration of preceding IPI (27-50 months) group IV and type of preceding pregnancy outcome.

\begin{tabular}{|c|c|c|c|c|c|c|c|c|c|}
\hline \multirow{3}{*}{$\begin{array}{l}\text { IPI } 27-50 \text { months began with } \\
\text { outcome of preceding pregnancy }\end{array}$} & \multicolumn{8}{|c|}{ Outcome of index pregnancy } & \multirow{3}{*}{ Total } \\
\hline & \multicolumn{2}{|c|}{ Induced abortion A } & \multicolumn{2}{|c|}{ Miscarriage B } & \multicolumn{2}{|c|}{ Still birth $\mathrm{C}$} & \multicolumn{2}{|c|}{ Live birth D } & \\
\hline & No. & $\%$ & No. & $\%$ & No. & $\%$ & No. & $\%$ & \\
\hline Induced abortion (A) & 1 & 5 & 2 & 10 & 1 & 5 & 16 & 80 & 20 \\
\hline Miscarriage (B) & 1 & 3.1 & 3 & 9.3 & 2 & 6.2 & 26 & 81.25 & 32 \\
\hline Still birth (C) & 1 & 3.5 & 1 & 3.5 & 3 & 10.7 & 23 & 82 & 28 \\
\hline Live birth (D) & 4 & 1.25 & 8 & 2.5 & 6 & 1.8 & 302 & 94 & 320 \\
\hline Total & 7 & 1.75 & 14 & 3.5 & 12 & 3 & 367 & 91.75 & 400 \\
\hline \multicolumn{10}{|c|}{ Reference category } \\
\hline IPI 27-50 months began with live birth & 4 & 1.25 & 8 & 2.5 & 6 & 1.8 & 302 & 94 & 320 \\
\hline
\end{tabular}

$\mathrm{p}=0.003$, Significant 
These all observation is showing that if socioeconomic and demographic variable is controlled then outcome of present pregnancy not only depend upon interpregnancy interval but also depend upon outcome of preceding pregnancy. So, outcome of previous pregnancy will also determine outcome of present pregnancy.

\section{DISCUSSION}

The study on "effects of interpregnancy interval and outcome of preceding pregnancy on present pregnancy outcome" was aimed to study the effect of birth spacing that is interpregnancy interval on outcome of pregnancy and how the outcome of preceding pregnancy affects the outcome of present pregnancy.

There are several factors affecting the outcome of pregnancy such as age, parity, prenatal care, education, socioeconomic status, whether pregnancy intended or no, birth spacing and outcome of previous pregnancy. These factors are controlled then outcome of index pregnancy not only depend upon interpregnancy interval and but also depend upon outcome of preceding pregnancy. ${ }^{5}$

In our sample $30 \%$ of IPIs of known duration are shorter than 15 months and nearly $14 \%$ are shorter than 6 months. Such shorter IPIs are much more likely then longer one to begin with a non-live birth. Compared with IPIs of 27-50 months, IPIs of $<6$ months are 4 times more likely to begin with an induced abortion, 3 times more likely to begin with a miscarriage, 2 times more likely to begin with a still birth. Other studies have found effect of short interval or IPI and effect of previous pregnancy outcome over present pregnancy outcome. DaVanzo J, Hale L, Razzaque A, Rahman M also found in their studies that short IPI are more likely begin with a non-live birth, they have found that IPI $<6$ months are 31 times more likely to begin with a miscarriage, 16 time more likely to begin with a still birth and 6 times more likely to begin with a induced abortion. Our finding that induced abortion is more likely after short IPIs that began with a live birth then IPI of 27-50 months. ${ }^{6}$

Other studies have found effects of short intervals on stillbirths and fetal death. Studies using data from Sweden found that very short (0-3 months) IPIs were associated with higher risks of stillbirth, although these relationships became somewhat weaker when maternal characteristics and preceding reproductive history were controlled. ${ }^{7-9}$

An investigation of world fertility survey (WFS) data from 40 developing countries. found IPIs of less than 9 months to be associated with higher risks of fetal death not controlling for other characteristics, but early fetal losses and stillbirths were combined in that study. In another study using the WFS data from eight countries, multivariate models produced similar results when controlling for maternal age at conception, pregnancy order, maternal schooling, and place of residence. ${ }^{10,11}$
A study in Bangladesh, however, found no relationship between late fetal death ( $\geq 28$ weeks of gestation) and short IPIs ( $<12$ months) compared with intervals longer than 24 months. A study in Ethiopia found that abortions and stillbirths were much more common among birth-tooutcome intervals less than 1 year among a sample of 1549 pregnancies, but no other variables were controlled, and spontaneous abortions were grouped with induced abortions. $^{12,13}$

The increased percentage of induced abortion associated with a short IPI after a live birth for IPIs $<6$ months following live birth is $11.6 \%$, undoubtedly reflect the fact that women did not intend to become pregnant so soon after a previous pregnancy. However, this is not likely to be the case for stillbirths or miscarriages, most of which are unintended outcomes. For these, their higher incidence following short IPIs after a previous live birth probably reflects the fact that the woman had inadequate time to recuperate from the previous pregnancy, although some miscarriages may be caused by women intentionally engaging in activities (e.g. vigorous physical activity) that may increase their chance of pregnancy loss or it may be the case that some induced abortions are reported as being miscarriages. A finding of increased percentage of adverse pregnancy outcomes after IPIs of less than 6 months is consistent with research that shows infant mortality to be higher for such intervals. ${ }^{14}$

Authors have shown that the effects of IPIs differ considerably depending on the type of outcome that began the interval. Previous research on the effects of IPIs has generally not distinguished the type of pregnancy outcome that began the interval. An exception is the study of Conde-Agudelo et al, that uses data on more than 250000 pregnancies in Latin America that followed abortions. ${ }^{15}$ That study found that short post-abortion IPIs (<6 months) are associated with increased risks of maternal anaemia, premature rupture of membranes, low birthweight, very low birthweight, preterm delivery, and very preterm delivery, but they were not associated with increased risks of fetal death. The study of CondeAgudelo et al, hypothesises that abortions, particularly induced abortions, may lead to reproductive tract infections, and these may lead to adverse pregnancy outcomes. However, the study was unable to distinguish between whether the preceding outcome was a spontaneous or induced abortion. Results of this study show that the risk of a subsequent induced abortion is relatively high when the preceding outcome is an induced abortion but relatively low when it was a miscarriage (or stillbirth). The fact that the study of Conde-Agudelo et al. combines the first two and cannot distinguish between them may explain why that study did not find that short post-abortion IPIs were associated with higher rates of fetal loss. ${ }^{15}$

Authors find that pregnancies after induced abortions are more likely to be terminated with a subsequent induced abortion, for IPIs $<6$ months rate of induced abortion 
$8.5 \%$, IPIs of $15-16$ months $4.3 \%$, IPIs of $15-26$ months $2.5 \%$ regardless of the duration of the IPI (up to 50 months). It appears that these women did not intend to become pregnant either time, regardless of the length of the interval between the pregnancies. Conde-Agudelo et al, hypothesise that the higher risks of adverse pregnancy outcomes they find following abortions (spontaneous and induced combined) might be because of infections caused by the abortion, particularly induced abortions.

Pregnancies after a miscarriage or stillbirth are more likely to result in a subsequent miscarriage or stillbirth, respectively, and this tends to occur irrespective of the interval between the pregnancies. This may be because of the physiological characteristics of the mother that are not measured in this study. A recent study in Sweden found a positive correlation in the likelihood of miscarriages across pregnancies. ${ }^{16,17}$

There are several reasons why short preceding IPIs may be associated with adverse pregnancy outcomes and why these effects might differ by the type of outcome that begins the interval. The maternal depletion hypothesis posits that women who become pregnant after a short interval are less able to provide nourishment during the second pregnancy because their bodies have had less time to recuperate from the previous pregnancy, and this might lead to reduced gestational duration, adverse pregnancy outcomes, and/or increased infant and child mortalities. For example, if women become pregnant again before folate restoration is complete, their subsequent offspring may be at a higher risk of folate insufficiency at the time of conception and throughout the pregnancy, leading to increased risks of neural tube defects, intrauterine growth restriction, and preterm birth. Also, the uterus needs time to recover after a pregnancy. Full-term pregnancies are more depleting than those that are of shorter gestation, and hence, short intervals that begin with a live birth or stillbirth should have a more detrimental effect than those that began with a miscarriage or induced abortion. Also, if the pregnancy that begins the interval results in a live birth and the child is breastfed, lactation will further deplete the mother nutritionally. Compared with clinical studies, however, the rates of induced abortion, miscarriage, and stillbirths appear to be underreported in this study. ${ }^{18,19}$

Several other possible limitations should be noted. Information needed to calculate the duration of IPIs (the date of the previous outcome and the date of the last menstrual period before the index pregnancy) is missing by some of the women of the observations in our sample, it could affect our results. In addition, the DSS defines miscarriages as spontaneous fetal losses that occur before 28 weeks since the last menstrual period. This is a longer gestation than is used in most definitions of miscarriages, and hence, some of findings of this study about 'miscarriages' may not hold if they were defined using a shorter gestation. ${ }^{20}$
Furthermore, the sample area for the study in rural and urban area of Gwalior and Chambal Division of Madhya Pradesh has access to unusually good maternal and child health care and family planning services. This may result in fewer NLB outcomes as a result of better prenatal care and in fewer unintended pregnancies because of the good family planning services. Studies similar to this one should be conducted in communities in developing countries with a more typical level of resources. Also, the finding of higher rates of induced abortion after very short intervals that began with a live birth may not hold in developed countries where women may wish to have births close together to minimise their time out of the labour force. In addition, future research should investigate the effect of pregnancy spacing and type of preceding pregnancy outcome on gestational duration, birthweight, and maternal morbidity and mortality.

\section{CONCLUSION}

The effect of interpregnancy interval and outcome of preceding pregnancy on outcome of present pregnancy is an observational study and conclusion is that woman whose inter pregnancy interval between 15-50 months after a preceding pregnancy outcome have a lower like hood of miscarriage and still birth. Than those shorter IPIs. After a previous live birth rate of IA are lowest for group III and group IV which suggest that woman in Gwalior and Chambal division of M.P., India prefer to have their birth spacing 2-5 years apart. The lowest rate of IA abortion occurs for IPIs of 27-50 months after a live birth. For IPI of 15-26 months following miscarriage is $2 \%$ and following still birth $3.3 \%$ which is consistent with the notion that such woman wants to have a birth fairly, quickly to "Replace" their recent unintentional fetal loss.

If the preceding pregnancy ended in an IA, the like hood of a subsequent is high regardless of duration of IPI. Woman who have had an IA should be counselled with regard to contraceptive option, so that they can avoid another unintended pregnancy. If the preceding pregnancy ended in a miscarriage or still birth, there is elevated risk that index pregnancy will end with same outcome. Regardless of the amount of time since the previous pregnancy ended. Woman with a preceding fetal loss deserve special attention in counselling and monitoring.

Funding: No funding sources Conflict of interest: None declared

Ethical approval: The study was approved by the Institutional Ethics Committee

\section{REFERENCES}

1. WHO. 2005. Antenatal care randomized trial: Manual for the implementation of the new model. Retrieved. 2007. Available at: 
http://www.who.int/reproductivehealth/publications/ RHR01_30/RHR_01_30_contents.en.html.

2. WHO. 2003. The world fertility report, executive Summery 1998-2000. Retrieved. 2007.Available at: http://www.un.org/esa/population/publications/ worldfertility/Executive_Summary.pdf.

3. Knodel J. Starting, stopping, and spacing during the early stages of fertility transition: The experience of German village populations in the 18th and 19th centuries. Demograp. 1987;24(2):143-62.

4. Kallan JE. Reexamination of interpregnancy intervals and subsequent birth outcomes: evident from U.S. linked birth/infant death records. Soc Biol Fall-Winter. 1997;44(3-4):205-12.

5. Setty-Venugopal V, Upadhyay UD. Birth spacing: three to five saves lives. Population Reports. Series L: Issues World Health. 2002(13):1-23.

6. DaVanzo J, Hale L, Razzaque A, Rahman M. Effects of interpregnancy interval and outcome of the preceding pregnancy on pregnancy outcomes in Matlab, Bangladesh. BJOG: 2007;114(9):1079-87.

7. USAID and WHO. 2008. Newborn health and Survival A Call to Action. Retrieved 2008. Available at: http://ww.docstoc.com/docs/67458/Newbornhealth-and-survival-a-call-to-action.

8. DeFranco EA, Stamilio DM, Boslaugh SE, Gross GA, Muglia LJ. A short interpregnancy interval is a risk factor for preterm birth and its recurrence. Am J Obstetr Gynecol. 2007;197(3):264-e1.

9. Abebe GM, Yohannis A. Birth interval and pregnancy outcome. East Afr Med J. 1996;73(8):552-5.

10. Swenson I. Relationships between pregnancy spacing, sex of infants, maternal age, and birth order, and neonatal and post-neonatal mortality in Bangladesh. Social Bio. 1981;28(3-4):299-307.

11. Stephansson O, Dickman PW, Cnattingius S. The influence of interpregnancy interval on the subsequent risk of stillbirth and early neonatal death. Obstetr gynecol. 2003;102(1):101-8.

12. Swenson I, Harper PA. The relationship between fetal wastage and pregnancy spacing in Bangladesh. Social Bio. 1978;25(3):251-7.
13. Kashanian M, Akbarian AR, Baradaran $H$, Shabandoust SH. Pregnancy outcome following a previous spontaneous abortion (miscarriage). Gynecol Obstet Invest. 2006;61(3):167-0

14. DaVanzo J, Hale L, Razzaque A, Rahman M. Effects of interpregnancy interval and outcome of the preceding pregnancy on pregnancy outcomes in Matlab, Bangladesh. BJOG. 2007;114(9):1079-87.

15. Conde-Agudelo A, Rosas-Bermúdez A, KafuryGoeta AC. Effects of birth spacing on maternal health: a systematic review. Am J Obstetr Gynecol. 2007;196(4):297-308.

16. Swenson I. Relationships between pregnancy spacing, sex of infants, maternal age, and birth order, and neonatal and post-neonatal mortality in Bangladesh. Soc Biol. 1981;28:299-307.

17. Rutstein SO, Johnson K, Conde-Agudelo A, RosasBermudez A. Effect of birth spacing on infant and child mortality: a systematic review and metaanalysis. World health organization consultation and scientific review of birth spacing. WHO, Geneva. 2005.

18. Casterline JB. Maternal age, gravidity, and pregnancy spacing effects on spontaneous fetal mortality. Soc Biol. 1989;36:186-212.

19. Kashanian M, Akbarian AR, Baradaran H, Shabandoust SH. Pregnancy outcome following a previous spontaneous abortion (miscarriage). Gynecol Obstet Invest. 2006;61:167-70.

20. Smits LJ, Essed GG. Short interpregnancy intervals and unfavorable pregnancy outcome: role of folate depletion. Lancet. 2001;358:2074-7.

Cite this article as: Soni S, Singh B, Agarwal V. Effects of interpregnancy interval and outcome of preceding pregnancy on present pregnancy outcome. Int J Reprod Contracept Obstet Gynecol 2019;8:1655-61. 